\title{
WAFER-LEVEL FABRICATION OF POWER INDUCTORS IN SILICON FOR COMPACT DC-DC CONVERTERS
}

\author{
Jiping $\mathrm{Li}^{1}{ }^{*}$, Victor Farm-Guoo Tseng ${ }^{1}$, Zhiming Xiao ${ }^{2}$, and Huikai Xie ${ }^{1}$ \\ ${ }^{1}$ Department of Electrical and Computer Engineering, University of Florida, Gainesville, FL, USA \\ ${ }^{2}$ Linear Technology Corporation, Milpitas, CA, USA
}

\begin{abstract}
This paper reports the design, fabrication and characterization of a novel power inductor embedded inside a silicon substrate and fabricated at wafer level. Such power inductors in silicon (PIiS) fully explore the capability of forming high-aspect-ratio silicon molds by DRIE for large-cross-section copper winding plating (as thick as the silicon wafers) while also utilizing high-resistivity magnetic composites. By completely using electroplating processes to form the copper coils and vias, the contact resistance between conductive layers can be minimized, and the quality factor can be improved significantly. This process also provides surface mounting pads for a compact converter assembly. Square shaped spiral inductors $\left(3 \times 3 \times 0.83 \mathrm{~mm}^{3}\right)$ were successfully fabricated, achieving a large inductance $(430 \mathrm{nH})$, low DC resistance $(84 \mathrm{~m} \Omega)$, and high quality factor $(21)$ at $6 \mathrm{MHz}$. The fabricated inductors were also assembled with a TI TPS62621 buck converter IC, and an efficiency of $83 \%$ was achieved.
\end{abstract}

\section{INTRODUCTION}

DC-DC converters are voltage regulators widely used in portable electronics and office facilities, where bulky magnetic components or inductors are usually the largest single volume contributor. Using higher operation frequency is one approach to minimize the size of power converter modules with low power storage and inductance requirements, but at the price of more integration challenges such as substrate parasitics, coupling noise, and increased losses, which further prompt the compact integration of all components into a single package.

Power System in Packaging (PSiP) and Power System on Chip (PSoC) are two major approaches for passives integration in modern power systems operated at high frequency range (3-20 MHz). For PSiP, power inductors and other passive components are integrated off chip inside a package. Technologies such as co-packaged inductors, inductors on PCB, LTCC or magnetic substrates, and inductors by wire bonding are all PSiP examples [1-4]. They generally have larger dimensions compared to on-chip solutions. On the other hand, PSoC is a monolithic integration approach, mostly using MEMS technologies to form power inductors directly on chip. Researchers have reported on-chip inductors employing air cores, sputtered or electroplated magnetic cores, laminated magnetic cores, or composite cores [5-9]. PSoC approaches emphasize on wafer-level batch integration of power inductors, providing minimum sizes and compact interconnections. However, the integration of passives on power IC chips complicates the fabrication process and suffers from several technical challenges, for example, the difficulty of fabricating thick windings $(>100 \mu \mathrm{m})$ and thick magnetic cores, or incorporating high-resistivity low-hysteresis-loss core materials with sufficient permeability at high frequencies.

In PSoC approaches, in-silicon techniques have been well explored by using the bulk silicon substrate to improve the inductor performance, either for large cross section conductors or for large volume magnetic cores [9, 10]. This work reports a new micromachining process that can fabricate PIiS inductors with thick windings and high-quality magnetic cores at wafer level. A wafer-level integration process can be applied to monolithically bond the PIiS power inductor with IC circuitry and hence build a compact power module.

\section{CONCEPT}

\section{Fully integrated power converter}

To cope with all the challenges at this high switching frequency era and still take advantage of the high throughput of semiconductor processes, this work proposes a power converter module based on a PIiS inductor as shown in Fig. 1.

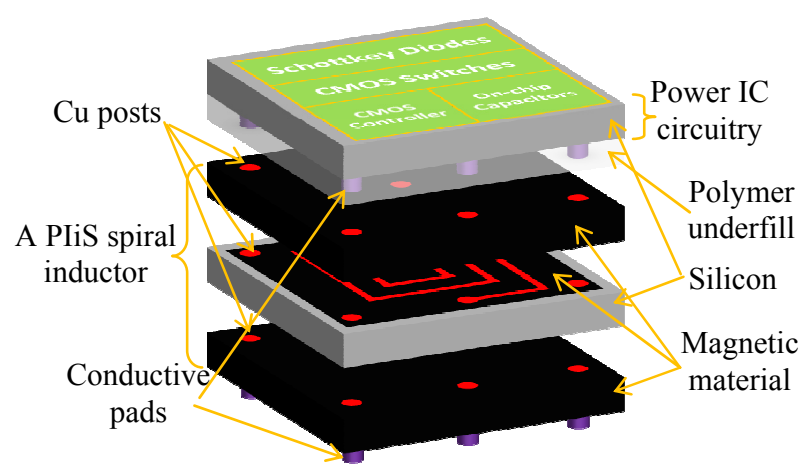

Figure 1: Concept of the fully integrated power converter with PIiS power inductor; $3 D$ explosive view.

Major benefits of this PIiS design can be summarized as the following. (1) The substrate molded conductors can be electroplated as thick as the substrate $(200-500 \mu \mathrm{m}$ thickness). Forming a thick magnetic core is also possible by thoroughly replacing the lossy substrate with high-resistivity and polymer-bonded magnetic materials, hence enabling high current capability ( $>2 \mathrm{~A})$. (2) Closed or quasi-closed magnetic path is formed in the three device layers to avoid extra losses and electromagnetic interferences. (3) Through substrate copper plating provides TSVs and good thermal paths as well, leading to high-degree integration and compact packaging. (4) Polymer based dielectric materials that are regularly used in packaging are chosen as the passivation as well as stress buffering layers. (5) The whole fabrication flow can be done at low temperatures $\left(<150^{\circ} \mathrm{C}\right)$ which is compatible with CMOS processes.

Compared to our prior work [9], one major improvement of the new process is using wafer-level plated copper posts instead of manually-placed solder balls for flip-chip bonding, which significantly reduces the contact resistances between conductive layers and increases the electrical contact reliability.

\section{FABRICATION}

\section{Polymer-bonded magnetic}

The magnetic material must have high resistivity and high permeability and can be applied at wafer level as well. Thus, a mixture of magnetic powders and polymer is employed. In this work, NiZn ferrite powders (FP350 from Powder Processing Technology, LLC, $89 \mathrm{wt} \%$ ) are first milled down from $10 \mu \mathrm{m}$ to $1-3 \mu \mathrm{m}$ size, and then mixed with PDMS (Sylgard 184 from Dow Corning, 11wt\%). After curing in an oven at $120^{\circ} \mathrm{C}$, this magnetic composite exhibits 
high resistivity, and the measured properties are as follows: $\rho>2$ $\mathrm{G} \Omega \cdot \mathrm{m}, \mathrm{H}_{\mathrm{c}}=15 \mathrm{Oe}, \mathrm{B}_{\mathrm{sat}}=0.2 \mathrm{~T}$, and $\mu_{\mathrm{r}}=8$.

\section{Process flow}

As illustrated in Fig. 2, the device fabrication starts with a 2 -inch, $280 \mu \mathrm{m}$-thick silicon wafer. First, a $0.8 \mu \mathrm{m}$-thick $\mathrm{SiO}_{2}$ layer is deposited on the backside for electrical isolation using plasmaenhanced chemical vapor deposition (PECVD). Next, a $1.0 \mu \mathrm{m}-$ thick $\mathrm{Cu}$ seed layer is sputtered on the backside, and then the $\mathrm{Cu}$ thickness is increased to $40 \mu \mathrm{m}$ through $\mathrm{Cu}$ electroplating (Fig. 2(1)). This thickness is sufficient to withstand multiple polishing steps. Next, the silicon wafer is etched through with a slightly negative angle by deep reactive ion etch (DRIE). After a $1.0 \mu \mathrm{m}$ conformal coating of PECVD $\mathrm{SiO}_{2}$, an anisotropic reactive ion etch (RIE) exposes the $\mathrm{Cu}$ seed layer at the trench bottom and leaves the oxide on the trench sidewalls (Fig. 2(2)). Then, a $\mathrm{Cu}$ electroplating process fills the silicon trenches with $\mathrm{Cu}$, and the over-plated parts are polished away (Fig. 2(3)). Subsequently, the silicon between the $\mathrm{Cu}$ windings is thoroughly removed by another DRIE etch, and the PDMS-bonded magnetic composite mixture is manually pressed into the newly formed trenches. Vacuum treatment is necessary to repel solvents and trapped air before curing the agent in an oven at $120^{\circ} \mathrm{C}$, and the overfilled magnetic composite is then polished away (Fig. 2(4)).

Another critical process is to fabricate tall $\mathrm{Cu}$ posts $(>200 \mu \mathrm{m})$ as the vias that can pass through the thick magnetic composites, which is accomplished by using multiple photoresist coatings, as shown in Fig. 2(5) and its intermediate steps). Fig. 3 is a photo of fabricated $\mathrm{Cu}$ posts. First, a $1.0 \mu \mathrm{m} \mathrm{Cu} / \mathrm{Cr}$ seed layer is sputtered on the magnetic composite. Then, four layers of AZ9260 are spin coated and cured gradually to a total thickness of 80-85 $\mu \mathrm{m}$. After exposure, this thick photoresist is developed in AZ 400K 1:2 for 6-7 minutes. $\mathrm{Cu}$ electroplating is then performed and slightly overfills the photoresist molds. This sequence of lithography and electroplating is then repeated until the $\mathrm{Cu}$ posts reach the desired height before removing the $\mathrm{Cu} / \mathrm{Cr}$ seed layer.

PDMS-bonded magnetic composites are pressed and vacuum-pumped onto the wafer again, and the over filled part is polished away to expose the electroplated $\mathrm{Cu}$ posts (Fig. 2(6)). A $30-40 \mu \mathrm{m}$ top $\mathrm{Cu}$ shield layer is pattered and electroplated (Fig. 2(7)). Then the above procedures are repeated on the backside to complete the PIiS inductor fabrication (Fig. 2 (8)).

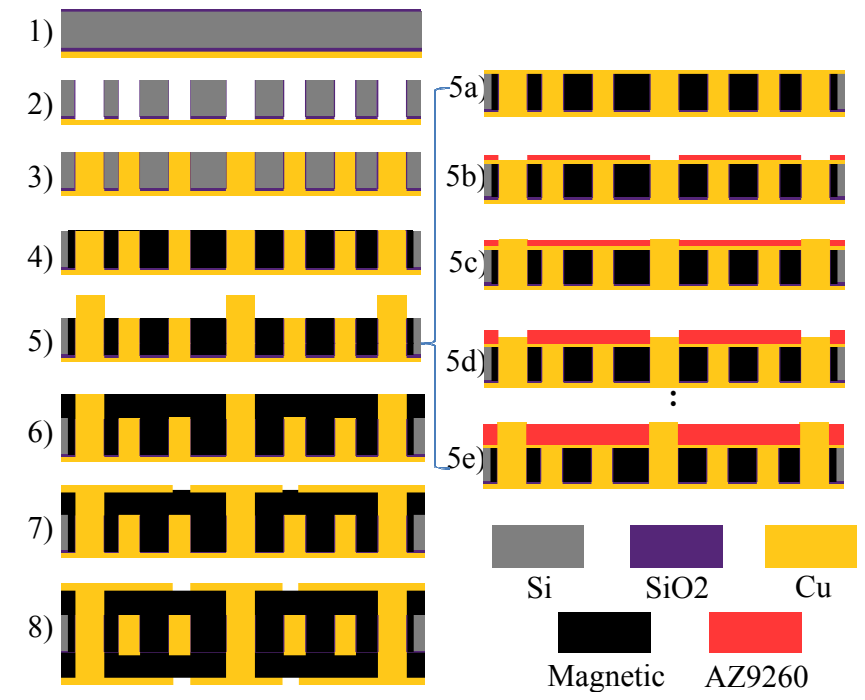

Figure 2: Cross-section view of the PIiS fabrication process.

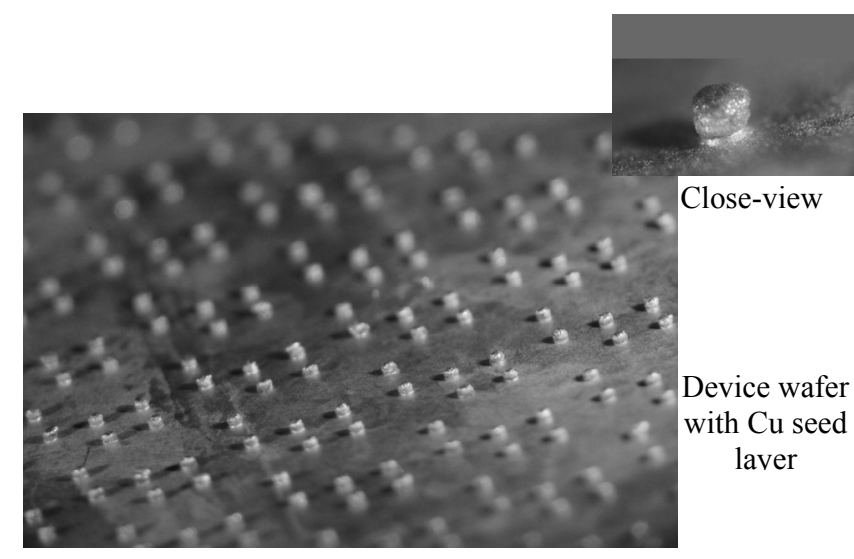

Figure 3: Side view of the Cu vias array on device wafer.

\section{Discussion on fabrication issues}

First, at step 5a) in Fig 2, the deposition of the $\mathrm{Cu}$ seed layer before the photolithography is needed to shield the thermal stresses originated from the magnetic material. Otherwise, cracks within the photoresist coating can be easily observed, with many bubbles appearing when coating another layer of photoresist, as shown in the photo in Fig. 4. For best interface adhesion between the seed layer and substrate, the wafer should be baked thoroughly for 5-6 minutes at around $110^{\circ} \mathrm{C}$ to remove any remnant moisture before $\mathrm{Cu} / \mathrm{Cr}$ sputtering. A $100-120 \AA \mathrm{Cr}$ layer is sufficient for promoting good adhesion. Other thick photoresists $(>200 \mu \mathrm{m})$ such as SU8 are also applicable with only one layer of coating required, and the extra $\mathrm{Cu}$ seed layer can be eliminated to further improve the interface performance.

Second, air can be easily trapped between the $\mathrm{Cu}$ coils during the magnetic filling process, e.g., steps 4), 6), and 8) in Fig. 2, and vacuum treatment is necessary to remove it before curing the PDMS-bonded magnetic composite. Multiple vacuum pumping cycles may be needed to ensure the air release. Fig. 5 shows one cross-section view of a fabricated 10-turn square spiral inductor with trapped air bubbles.

Third, the manual pressing process may cause the soft copper posts to become inclined or detached, as shown in Fig. 5. Therefore, careful control of the seed layer etching time is important to have a sufficient remaining $\mathrm{Cu}$ post diameter, as well as a large enough dimension design.

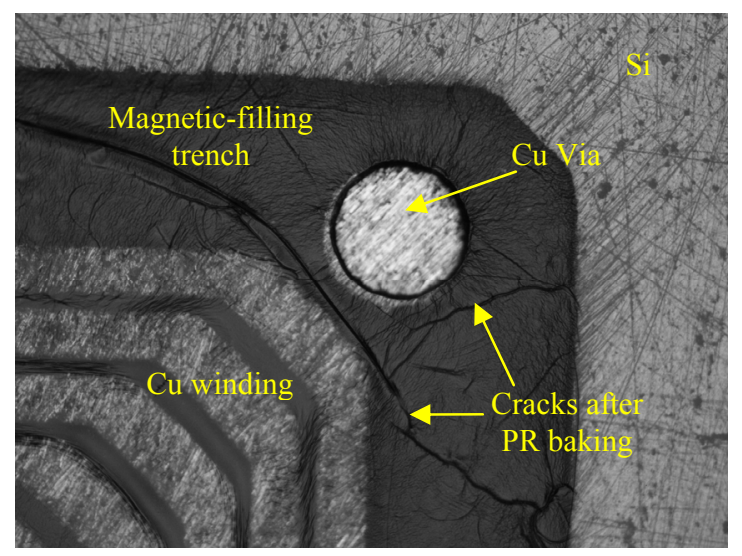

Figure 4: Top view of the stress accumulation problem after photoresist baking. 


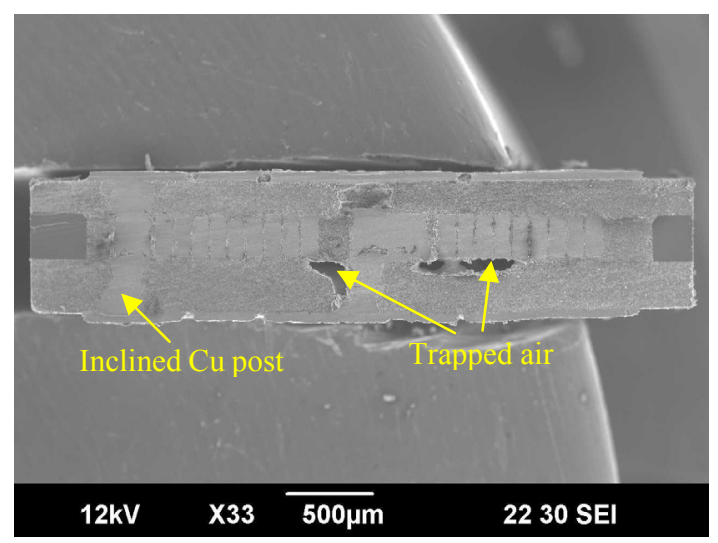

Figure 5: Cross-section view of a 10-turn PIiS power inductor with trapped air and inclined $\mathrm{Cu}$ post.

\section{RESULTS}

\section{Inductor characterization}

The PIiS inductors have been successfully fabricated and tested. Fig. 6 and 7 show the SEM pictures of the entire device and the cross section of a fabricated device. For this 10-turn square shaped spiral PIiS inductor, the thicknesses of the top magnetic core, copper winding and bottom magnetic core are $270 \mu \mathrm{m}, 280 \mu \mathrm{m}$, and $200 \mu \mathrm{m}$, respectively. The measured inductance, $\mathrm{Q}$ and $\mathrm{AC}$ resistance of the PIiS inductor versus frequency are plotted in Fig. 8, where $\mathrm{L}=430 \mathrm{nH}, \mathrm{R}_{\mathrm{dc}}=84 \mathrm{~m} \Omega, \mathrm{R}_{\mathrm{ac}}=792 \mathrm{~m} \Omega$, and $\mathrm{Q}=21$ at $6 \mathrm{MHz}$.

Compared with our prior work [9], the newly fabricated square spiral inductor has a similar size $(3 \mathrm{~mm} \times 3 \mathrm{~mm})$ but with much less resistance and higher inductance. Square spiral inductors are more area efficient than circular spiral ones. The magnetic layer is thicker on one side ( $270 \mu \mathrm{m}$ vs $200 \mu \mathrm{m})$, which leads to higher inductance. For the lower resistance, there are several factors contributing to that. First, the windings are taller $(280 \mu \mathrm{m}$ vs $200 \mu \mathrm{m})$ than our previous circular design, and they are also become wider (around 5 $\mu \mathrm{m})$ due to the undercut during the DRIE process. Second, electroplating $\mathrm{Cu}$ posts instead of placing solder balls reduces contact resistance between conductive layers significantly. Third, the resistivity of electroplated copper is lower than that of solder balls.

The PIiS is compared to other works in Table 1 and it has achieved low DC resistance, large inductance and high Q simultaneously.

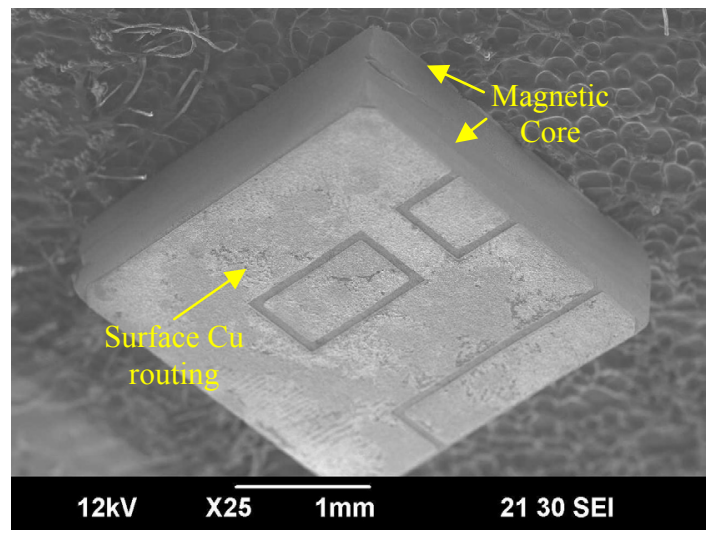

Figure 6: Side View of a $3 \times 3 \times 0.83 \mathrm{~mm}^{3}$ PIiS power inductor.

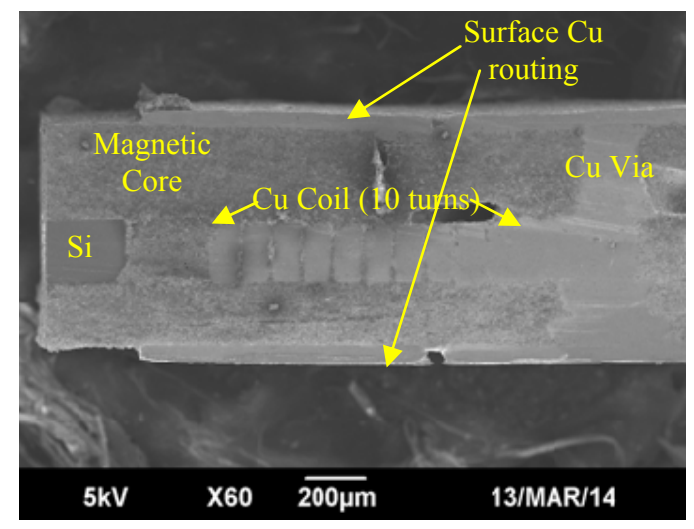

Figure 7: Cross-section view of a 10-turn PIiS power inductor.

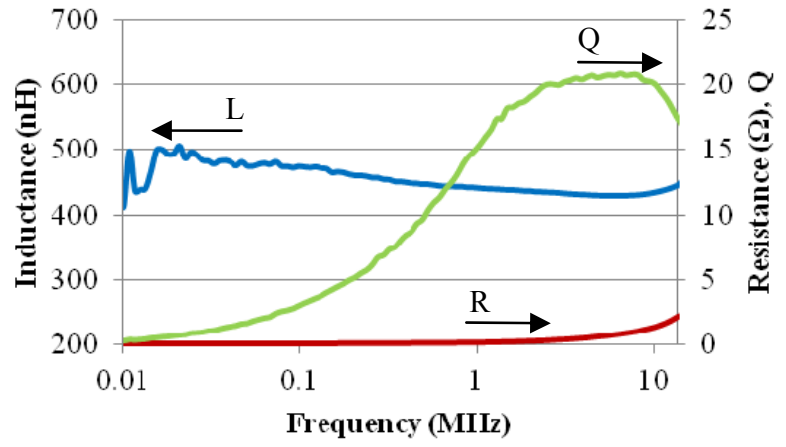

Figure 8: Inductance, $Q$ and $A C$ resistance verse frequency of a 10-turn PIiS power inductor.

Table 1: PIiS power inductor compared to other works with mm3-scale sizes..

\begin{tabular}{|l|l|l|l|l|l|}
\hline Inductors & \multicolumn{1}{|c|}{ Core } & $\begin{array}{c}L \\
(\mathrm{nH})\end{array}$ & $\begin{array}{c}\text { DCR } \\
(\mathrm{m} \Omega)\end{array}$ & \multicolumn{1}{|c|}{$Q_{\max }$} & $\begin{array}{l}\text { Area } \\
\left(\mathrm{mm}^{2}\right)\end{array}$ \\
\hline This work & NiZn+PDMS & $\mathbf{4 3 0}$ & $\mathbf{8 4}$ & $\mathbf{2 0 . 8 @ 6 M H z}$ & $\mathbf{3 \times 3}$ \\
\hline Prior [9] & NiZn+PDMS & 390 & 140 & $10 @ 6 \mathrm{MHz}$ & $3 \times 3$ \\
\hline On-Si [6] & FeCo & 55 & 100 & $13.8 @, 20 \mathrm{MHz}$ & $3 \times 3$ \\
\hline On-Si [7] & NiFe & 100 & 300 & $2.1 @ 1 \mathrm{MHz}$ & $4 \times 1$ \\
\hline In-Si [11] & SU8 & 60 & 399 & $17.5 @ 70 \mathrm{MHz}$ & $6 \times 6$ \\
\hline On-Si [5] & Air & 130 & 695 & $15 @ 160 \mathrm{MHz}$ & $1 \times 1$ \\
\hline
\end{tabular}

\section{Converter performance}

A PIiS has been bonded on a TI TPS62621 (600 mA, $6 \mathrm{MHz}$ high-efficiency step-down converter) buck converter evaluation board, as shown in Fig. 9. The measured efficiencies versus load currents and temperatures are plotted in Figs. 10 and 11.

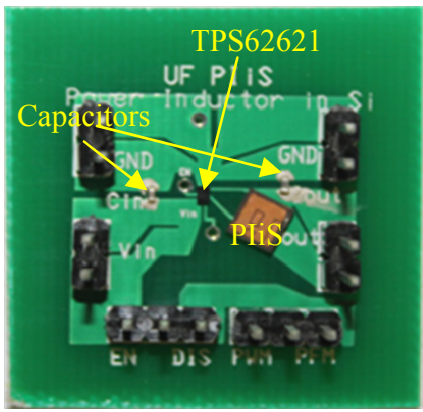

Figure 9: The TPS62621 buck converter evaluation board based on PIiS power inductor. 


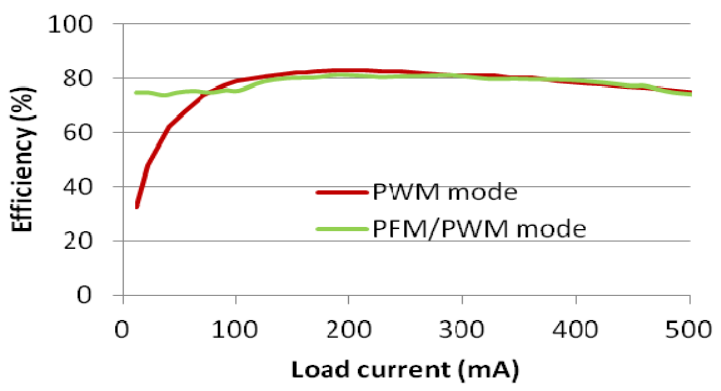

Figure 10: Efficiency vs. load current measurements (3.6/1.8V Vin/Vout).

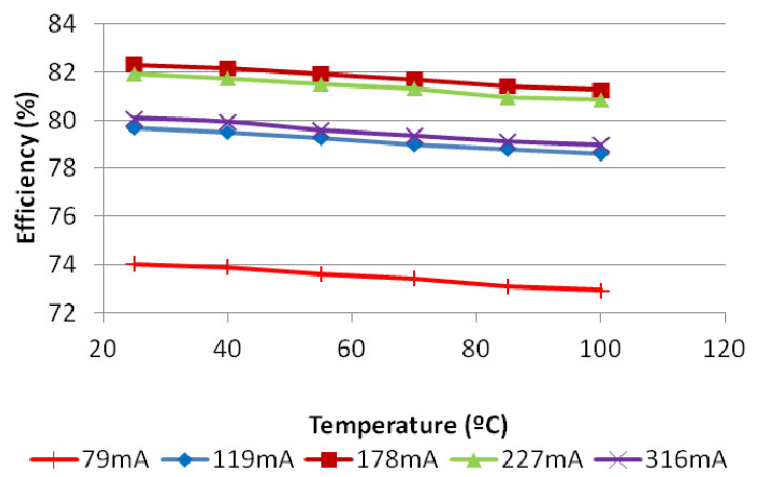

Figure 11: Efficiency vs. temperature measurements (3.6/1.8V Vin/Vout).

The buck converter module successfully delivered $600 \mathrm{~mA}$ at $1.8 \mathrm{~V}$ with an $83 \%$ maximum efficiency (PWM mode) at $6 \mathrm{MHz}$, which is comparable to commercial products and can be further improved with better packaging. The $3 \%$ loss reduction compared with our prior work is mainly benefited from the lower DC and AC resistances. A wide load current range (120-380 mA) for high efficiency $(80-83 \%)$ was also observed.

For loss breakdown, at 3.6/1.8 V input/output voltage and $129 / 214 \mathrm{~mA}$ input/output current, the measured efficiency is $82.9 \%$ which corresponds to $79 \mathrm{~mW}$ total loss. The calculated inductor ripple current is $174.4 \mathrm{~mA}$. Thus, the inductor's DC and AC losses are about $3.9 \mathrm{~mW}$ and $8 \mathrm{~mW}$, respectively. The TPS62621 regulator has a rated efficiency of $90 \%$ which accounts for about $46.5 \mathrm{~mW}$ loss. Adding up these component losses, the module has a $58.4 \mathrm{~mW}$ power loss without considering the losses from core hysteresis, trace resistances on board, and capacitor parasitics.

\section{CONCLUSION AND FUTURE WORK}

Wafer-level integration of power inductors in silicon (PIiS) for high efficiency, high frequency, and compact DC-DC power converters has been successfully demonstrated. PIiS power inductors have been successfully fabricated with the IC-compatible, low-cost micromachining process. Through-substrate silicon trenches with an aspect ratio up to 20:1, obtained by DRIE, are used for $\mathrm{Cu}$ electroplating molds. After $\mathrm{Cu}$ electroplating and polishing, the $\mathrm{Cu}$ windings have the same thickness as the silicon substrate. $\mathrm{Cu}$ posts up to $270 \mu \mathrm{m}$, which pass through the thick magnetic composites, are also realized using a sequential plating process. Thus, the PIiS inductors simultaneously achieve low DC resistance $(84 \mathrm{~m} \Omega)$, large inductance $(430 \mathrm{nH})$ and high Q (21).

The PIiS power inductor has been successfully assembled on a TI buck converter evaluation board and delivered $600 \mathrm{~mA}$ at $1.8 \mathrm{~V}$ with an $83 \%$ maximum efficiency at $6 \mathrm{MHz}$. Furthermore, the surface $\mathrm{Cu}$ pads on the PIiS power inductors are well prepared for mounting other IC components. A fully integrated power converter can be implemented with size-matched PIiS inductors and IC regulators, and much higher power density and smaller size can be achieved.

\section{ACKNOWLEDGEMENTS}

The authors would like to thank Linear Technology Corporation for technical and funding supports, and Nanoscale Research Facility and Interdisciplinary Microsystems Group of the University of Florida for device fabrication and characterization. Travel support has been generously provided by the Transducers Research Foundation (TRF).

\section{REFERENCES}

[1] E. Waffenschmidt and J. A. Ferreira, "Embedded passives integrated circuits for power converters," in IEEE 33rd Annu. Power Electronics Specialists Conf.(pesc 02), 2002, pp. 12-17 vol.1.

[2] M. H. Lim, J. D. Van Wyk, F. C. Lee, and K. D. T. Ngo, "A Class of Ceramic-Based Chip Inductors for Hybrid Integration in Power Supplies," IEEE Trans. Power Electron., vol. 23, pp. 1556-1564, 2008.

[3] M. Wens and M. Steyaert, "A fully-integrated 0.18um CMOS DC-DC step-down converter, using a bondwire spiral inductor," in IEEE Custom Integrated Circuits Conf. (CICC 2008), 2008, pp. 17-20.

[4] Q. Li, M. Lim, J. Sun, A. Ball, Y. Ying, F. C. Lee, et al., "Technology roadmap for high frequency integrated DC-DC converter," in IEEE 6th Int. Power Electronics and Motion Control Conf. (IPEMC '09), 2009, pp. 1-8.

[5] C. D. Meyer, S. S. Bedair, B. C. Morgan, and D. P. Arnold, "Ultra-miniaturized power converter modules using micromachined copper scaffolds," IEEE Int. Conf. on Micro Electro Mechanical Systems (MEMS, Hilton Head), 2012.

[6] T. Liakopoulos, A. Panda, M. Wilkowski, A. Lotfi, K. H. Tan, L. Zhang, et al., "Introducing FCA, a new alloy for Power Systems on a chip and Wafer Level Magnetic applications," in 13th Int. Conf. on Electronic Packaging Technology and High Density Packaging (ICEPT-HDP), 2012, pp. 949-954.

[7] C. H. Ahn and M. G. Allen, "A comparison of two micromachined inductors (bar- and meander-type) for fully integrated boost DC/DC power converters," IEEE Trans. Power Electron., vol. 11, pp. 239-245, 1996.

[8] B. Orlando, R. Hida, R. Cuchet, M. Audoin, B. Viala, D. Pellissier-Tanon, et al., "Low-Resistance Integrated Toroidal Inductor for Power Management," IEEE Trans. Magn., vol. 42, pp. 3374-3376, 2006.

[9] M. Wang, J. Li, K. D. T. Ngo, and H. Xie, "A Surface-Mountable Microfabricated Power Inductor in Silicon for Ultracompact Power Supplies," IEEE Trans. Power Electron., vol. 26, pp. 1310-1315, 2011.

[10] D. Yao, et al., "Microfabricated V-Groove Power Inductors Using Multilayer Co-Zr-O Thin Films for Very-High-Frequency DC-DC Converters," IEEE Trans. Power Electron., vol. PP, pp. 1-1, 2011.

[11] X. Yu, et al., "Silicon-embedded 3D toroidal air-core inductor with through-wafer interconnect for on-chip integration," in IEEE 25th Int. Conf. on Micro Electro Mechanical Systems (MEMS), 2012, pp. 325-328.

\section{CONTACT}

*Jiping Li: jipingli@yahoo.com 